\title{
ORAL MUCOSA LESIONS AND ORAL SYMPTOMS IN INFLAMMATORY BOWEL DISEASE PATIENTS
}

\author{
Nuno LARANJEIRA', Jorge FONSECA1,2, Tânia MEIRA², João FREITAS²; \\ Sara VALIDO ${ }^{1}$ and Jorge LEITÃ ${ }^{3}$
}

\begin{abstract}
Background - Inflammatory Bowel Disease is known for its extra intestinal manifestations, the oral cavity is no exception. Objectives - The aim of this study was to evaluate the association between Inflammatory Bowel Disease and oral mucosa lesions and symptoms, and complementary to evaluate their possible relation with oral hygiene, smoking habits, drug therapy, duration and activity of the disease. Methods - Patients were selected from the Gastroenterology Clinic of a Portuguese tertiary referral hospital. This sample consisted of 113 patients previously diagnosed with ulcerative colitis or Crohn's disease along with a control group of 58 healthy individuals that were accompanying the study group patients to their appointments. Clinical interviews and clinical examinations were performed for data collection. Results - The patients in the study group were more affected by oral symptoms $(P=0.011)$, and showed a trend towards a higher incidence of oral mucosal lesions, even though statistical significance was not reached $(8.8 \%$ versus $3.4 \%$ in the control group; $P=0.159$ ). Patients in active phase were the most affected. No differences were detected between Crohn's disease and ulcerative colitis, or concerning smoking habits. The corticosteroid and immunosuppressant therapy seemed to increase the incidence of oral symptoms $(P=0.052)$. The oral mucosa lesions increased and the oral symptoms decreased over the course of the disease, however without statistical significance. Conclusion - Oral mucosa's lesions and oral symptoms were positively associated with Inflammatory Bowel Disease, mainly during disease activity periods and conceivably, associated with corticosteroid and immunosuppressant therapy.
\end{abstract}

HEADINGS - Inflammatory bowel diseases. Aphthous stomatitis. Mouth mucosa.

\section{INTRODUCTION}

Inflammatory bowel disease (IBD) is a group of chronic conditions affecting the digestive tract in different locations ${ }^{(11)}$. The mechanisms underlying the disease are not yet fully understood and its incidence has been increasing since the end of the past century, with important consequences for public health ${ }^{(26)}$.

Crohn's disease (CD) and ulcerative colitis (UC) are the most common presentations of IBD $^{(12)}$. Both are characterized by chronic inflammation at intestinal and systemic level that seems to arise in response to an abnormal immunological reaction to the intestinal microbiota or other stimuli in susceptible individuals ${ }^{(3,22)}$. Throughout its course IBD is also characterized by periods of activity and remission and features a wide variety of manifestations at intestinal and extra-intestinal sites ${ }^{(1,8,12)}$. According to some authors, $25 \%-30 \%$ of the patients diagnosed with IBD have at least one extra-intestinal manifes- tation, being the oral cavity one of the most affected areas $^{(1,8,21)}$. The oral lesions include affections in the mucosa, periodontal tissues and tooth tissue, and have been said to play a role as an early indicator of IBD or at least as concomitant manifestations that could help with the diagnose ${ }^{(6,10,12,19,24)}$.

In general, oral mucosal lesions described in the literature may arise either in patients with $\mathrm{CD}$ or UC and may be specific or nonspecific for these pathologies $^{(6,8,24)}$. Some authors cite diffuse swellings of the oral and perioral tissues as the most prominent features ${ }^{(18)}$ but there have been reports of a great variety of pathological features in this patients ${ }^{(2,15)}$. Furthermore, it has been observed a higher prevalence of other oral symptoms as halitosis, nausea, xerostomia and regurgitation in patients with $\mathrm{IBD}^{(15)}$.

The aim of this study was to evaluate the association between IBD and oral mucosal lesions and symptoms, and complementary to evaluate their possible relation with oral hygiene, smoking habits, drug therapy, duration and activity of IBD.

\footnotetext{
Declared conflict of interest of all authors: none Disclosure of funding: no funding received

Egas Moniz Interdisciplinary Research Center, CiiEM, Egas Moniz Health Science Institute, Almada; ${ }^{2}$ Gastroenterology Service, Garcia de Orta Hospital, Almada; ${ }^{3}$ Institute of Health Sciences, Portuguese Catholic University, Viseu. Portugal.

Correspondence: Nuno Laranjeira. Instituto Superior de Ciências da Saúde Egas Moniz, Campus Universitário, Quinta da Granja, Monte de Caparica, 2829 - 511 , Caparica Almada, Portugal. E-mail: nunolaranjeira@hotmail.com
} 


\section{METHODS}

The study was conducted at General Gastroenterology and Inflammatory Disease Clinic of the Hospital Garcia de Orta (HGO), in Almada, Portugal. The protocol used for data collection was previously reviewed and approved by the Ethics Commission of HGO.

Patients who had been previously diagnosed with ulcerative colitis or Crohn's disease and who agreed to participate in this study were selected, having healthy individuals which were accompanying the study group patients to their appointments as the control group. Informed consent was obtained from all participants and the study design was in accordance with the Declaration of Helsinki.

Exclusion criteria were: patients under 18 years old, pregnant women, edentulous patients, patients with fixed orthodontic appliances, patients in need of prophylaxis for bacterial endocarditis, patients without a clear diagnosis of ulcerative colitis or Crohn's disease and patients with other diseases that could interfere with the variables in study.

The assessment of disease activity was previously performed by the HGO gastroenterology team according to the Harvey-Bradshaw Index ${ }^{(14)}$ for $\mathrm{CD}$ and according to the Montreal Index of Activity ${ }^{(23)}$ for UC. The diseases were considered inactive for scores of 5 or less in the Harvey-Bradshaw Index (CD) and for S0 ratings in the Montreal Index of Activity (UC).

The patients were divided in five groups referring to the drug therapy: untreated; under salicylate therapy; under corticosteroids therapy; treated with immunosuppressant drugs - azathioprine and cyclosporine - and under biological therapy - infliximab and adalimumab. Patients treated with more than one drug were included in the group that most influences the evolution of the disease. In increasing order: salicylates, corticosteroids, immunosuppressant drugs, biological therapy.

Two groups were considered for the assessment of smoking habits: smokers and non-smokers. All individuals who reported smoking habits regardless of frequency were considered in the smokers group. Ex-smokers were classified as non-smokers.

Disease duration was divided into three ranges: short term [up to 3 years]; average term [more than 3 to 9 years] and long term [longer than 9 years].

\section{Clinical data}

Patients admitted in the study answered a standardized questionnaire, in order to record the following information: age, gender, medical history, medication, smoking habits and oral hygiene habits.

Patients were also asked to indicate all the oral symptoms they have experienced recently from a list containing: xerostomia, halitosis, dysphagia, regurgitation, dysgeusia and acid taste.

\section{Oral examination}

Data was collected by a team directed by the main inves- tigator. Clinical observation was always performed by the same examiner, while another research team element pointed out data simultaneously, eliminating protocol differences and preserving the results agreement.

The search for oral lesions in the mucosa and surrounding soft tissues, started at the lips vermillion, then labial mucosa, followed by the buccal mucosa, gums, palate and tongue in this specific order. All the oral lesions detected were then registered.

\section{Statistical analysis}

The data collected from the questionnaires and intraoral examination was inserted in Microsoft Excel ${ }^{\mathrm{TM}}$ and SPSS ${ }^{\mathrm{TM}}$ (Statistical Package for Social Sciences) for analysis and statistical processing.

To describe and summarize the data obtained in the sample, descriptive statistics measures were performed. Kolmogorov-Smirnov tests were used to test the normality of the sample; Spearman correlation tests, Fisher exact test and Kruskal-Wallis tests were then used to verify the correlation strength between these variables with a confidence level of $95 \%$.

\section{RESULTS}

\section{Sample characterization}

Initially, 183 individuals were observed, from which 12 did not meet the established criteria. As a result, a final number of 171 individuals were included in the study - $113(66.1 \%)$ patients in the study group and $58(33.9 \%)$ individuals in the control group.

The average age of the sample was $45.5 \pm 16.9$ years, the minimum age was 19 years old and maximum 81 year old. Eighty-five (49.7\%) individuals were male and $86(50.3 \%)$ were female. In the total sample there was $85.4 \%(n=146)$ of non-smoker subjects, and 14.6\% $(\mathrm{n}=25)$ of smoker patients.

The IBD study group consisted of $57(50.4 \%)$ males and $56(49.6 \%)$ females, with a mean age of $44.5 \pm 17.2$ years, with a minimum of 19 and maximum of 81 years old. $83.2 \%$ $(n=94)$ of this group were non-smoker patients, against 16.8\% $(n=19)$ smokers.

A total of $15 \%(n=17)$ of the 113 patients were undergoing active disease, and $85 \%(n=96)$ were in remission. The most common diagnosis was Crohn's disease in 57.5\% $(n=65)$, the remaining patients $(n=48)$ were diagnosed with ulcerative colitis (Table 1).

The control group was composed of $28(48.3 \%)$ male and $30(51.7 \%)$ female individuals. The mean age was $47.4 \pm 16.3$ years, with a minimum of 19 and maximum of 77 years old. Fifty-two $(89.7 \%)$ were non-smoking, against $6(10.3 \%)$ smokers (Table 1).

All individuals reported brushing their teeth at least once a day (on average 2 brushings in the study group and 1.8 in the control group). The use of dental floss has been reported in $20.4 \%(n=23)$ of the study group and $8.6 \%(n=5)$ of the control group. The mouthwashes were not regularly used by the majority of the patients (Figure 1). 
TABLE 1. Demographic data of the groups (CD, UC and Control) for our sample

\begin{tabular}{lccccc}
\hline & $\begin{array}{c}\mathrm{CD} \\
(\mathbf{n}=65)\end{array}$ & $\mathbf{P 1}$ & $\begin{array}{c}\text { UC } \\
(\mathbf{n}=48)\end{array}$ & P2 & $\begin{array}{c}\text { Controls } \\
(\mathbf{n}=58)\end{array}$ \\
\hline Age & 41.1 & 0.030 & $\begin{array}{c}49.2 \\
(18.4)\end{array}$ & 0.599 & $\begin{array}{c}47.4 \\
(16.3)\end{array}$ \\
Masculine & 32 & 0.916 & 25 & 0.696 & 28 \\
Feminine & 33 & 0.916 & 23 & 0.696 & 30 \\
Caucasian & 63 & 0.340 & 47 & 0.376 & 57 \\
Black & 2 & $<0.001$ & 0 & n.d. & 1 \\
Smoker & 13 & $<0.001$ & 6 & $<0.001$ & 6 \\
Non-smoker & 52 & 0.004 & 42 & 0.001 & 52 \\
Active disease & 9 & - & 8 & - & -
\end{tabular}

$(\chi)$ Standard deviation of respective datasets. (P1): significance of the differences between CD and Control; (P2): significance of the differences between control and UC.

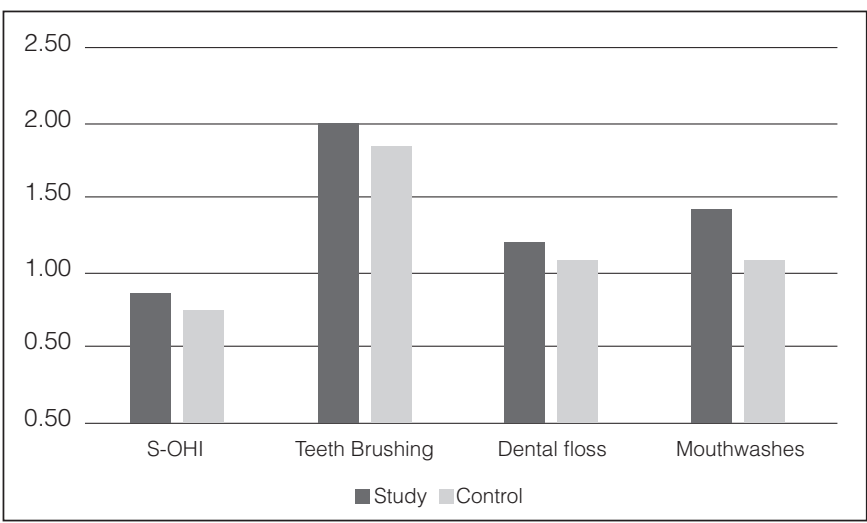

FIGURE 1. Simplified Oral Hygiene Index, number of daily brushings, interdental cleaning and use of mouthwashes in the study and control groups.

\section{Clinical data}

\section{Case-control comparison}

In the study group we detected the presence of aphthous ulcers $(n=10)$, gingival swelling $(n=1)$ and angular cheilitis $(\mathrm{n}=1)$. Only aphthous ulcers and gingival swelling were found on the control group individuals, $(n=1)$ each. (Figure 2$)$

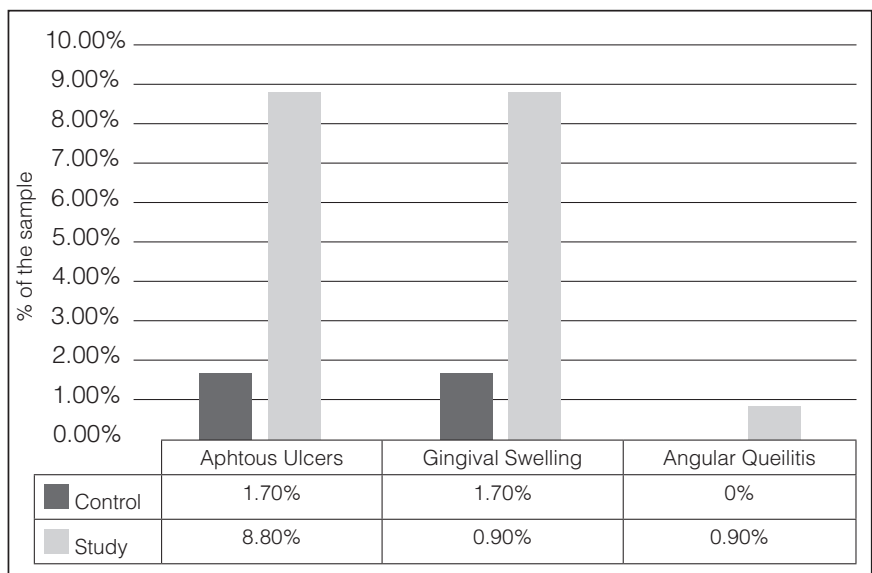

FIGURE 2. Distribution of lesions of the oral mucosa in the study and control groups.
Lesions of the oral mucosa showed higher prevalence in the study group compared with the control group $(8.8 \%$ versus $3.4 \%$ ), even though this difference was not statistically significant $(P=0.159)$.

The IBD group and the control group have also prevailed in several oral symptoms, such as halitosis, regurgitation, acid taste, xerostomia, dysphagia and dysgeusia. (Figure 3) The differences in the prevalence of oral symptoms in the study group when compared with the control group as presented in Figure 3, was statistically significant $(P=0.011)$. Patients with IBD reported oral symptoms in $54.9 \%$ of cases compared with only $29.3 \%$ of the control group. Dysphagia $(P=0.038)$ revealed to have a statistically significant association with IBD. Even when analyzed separately, none of the other symptoms showed statistical significance for this association.

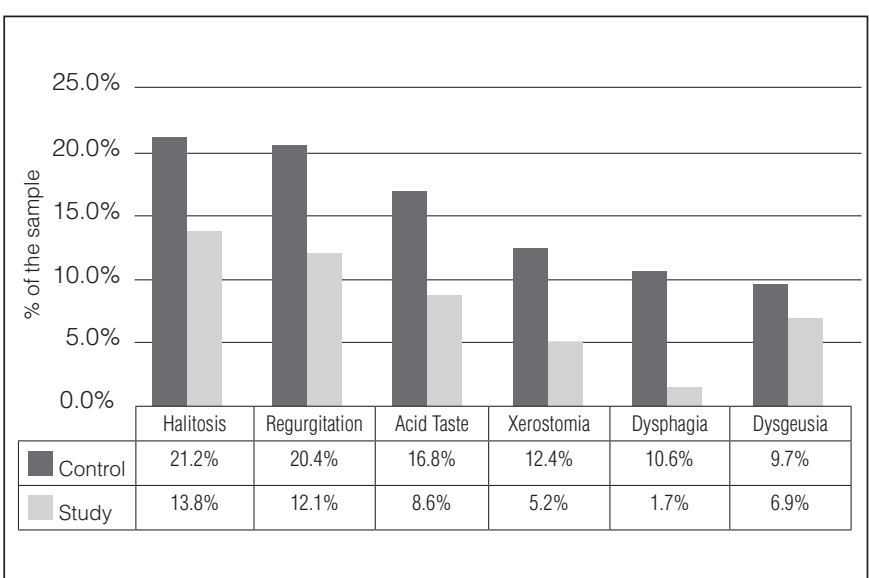

FIGURE 3. Distribution of oral symptoms in the study and control groups.

\section{Activity of IBD}

The oral mucosa lesions revealed a higher prevalence in the active phase of the disease $(35.3 \%$ versus $4.2 \%)$, $(P<0.001)$. Aphthous ulcers proved to be the only type of affections with a statistically significant association to the active phase $(P=0.001)$, with $35.3 \%$ of patients in the active stage diagnosed with this type of oral lesion versus $4.2 \%$ in remissive phase.

Patients in active phase reported oral symptoms in 70.6\% of cases compared to only $52.1 \%$ of the patients in remission. This represented a statistically significant difference $(P=0.001)$. Dysphagia $(P=0.018)$, regurgitation $(P=0.044)$ and acid taste $(P=0.038)$ revealed to have a statistically significant association with the active phase of IBD, even when analyzed separately.

\section{Crohn's disease vs ulcerative colitis}

The oral mucosa lesions did not reveal a statistically significant difference in incidence between the patients diagnosed with $\mathrm{CD}$ and patients diagnosed with UC, $(P=0.959)$. The oral symptoms did not show statistically significant difference between the groups with $\mathrm{CD}$ and UC either $(P=0.697)$. 
When analyzed separately neither of oral mucosa lesions or symptoms had a statistically significant relation with $\mathrm{CD}$ or UC.

\section{Pharmacotherapy}

Untreated patients at the time of examination revealed no incidence of oral mucosa lesions $(0 \%)$ and patients under corticosteroids treatment were the most affected by these lesions $(22 \%)$. Nevertheless, considering all the different types of medication used by the patients, the pharmacological therapy of IBD did not show a statistically significant relation with the presence of lesions of the oral mucosa $(P=0.711)$.

Individuals that were not under any type of medication also revealed less incidence of oral symptoms (38.5\%). Patients taking salicylates were the least affected by these symptoms $(50 \%)$, among medicated patients. On the opposite, $66.7 \%$ of the patients under Immunossupressants and Corticosteroids reported oral symptoms. In spite of these results, there was no statistically significant relation between oral symptoms and the pharmacological therapy of $\operatorname{IBD}(P=0.052)$.

\section{Smoking habits}

Non-smokers were the most affected by lesions of the oral mucosa with $9.57 \%(\mathrm{n}=9)$, compared to $5.26 \%(\mathrm{n}=1)$ of the smokers group. This relation was not statistically significant $(P=0.199)$.

When assessing the presence of oral symptoms between smoker patients and non-smoking patients no statistically significant relation was observed $(P=0.595)$.

When analyzed separately neither of oral mucosa lesions or symptoms had a statistically significant relation with smoking habits.

\section{Disease duration}

The different types of oral mucosa lesions showed a slight increasing tendency in incidence over the course of IBD, however, not in a statistically significant way $(P=0.670)$.

Oral symptoms decreased over the course of the disease, still this decrease was also not statistically significant $(P=0.720)$.

When analyzed separately neither of oral mucosa lesions or symptoms had a statistically significant relation with the disease duration.

\section{DISCUSSION}

This was the first large study on oral health of Portuguese IBD patients, focusing a wide range of oral symptoms and mucosal lesions. In our study, patients within IBD group presented a higher prevalence of oral mucosal lesions when compared with the control group, supporting what was previously reported in the literature ${ }^{2,5,12,15,25)}$, although in our case without statistical significance. Patients with IBD often present more oral mucosal lesions than healthy controls, in accordance with the results of our study.
Few authors have studied the relation between IBD and its possible oral symptoms. The study by Katz and colleagues ${ }^{(15)}$ was the first to establish this relation in a sample of 54 patients with IBD and 42 healthy subjects. As in our results, this study found that patients with IBD were more likely to experience oral symptoms when compared with a control group of healthy individuals. More recently, other authors have confirmed the same findings for patients with $\mathrm{UC}^{(7)}$.

In the active phase of the disease, aphthous ulcers, proved to be the most common type of lesion in the oral mucosa in our study $(P=0.001)$, as already reported by some authors ${ }^{(14,18)}$. In those studies, no further association between any other type of oral mucosa lesions and the active phase of IBD was established. Although these data are in agreement with our results, other authors ${ }^{(5,12)}$ in similar studies have not identified a correlation between activity of IBD and any type of oral mucosa lesions. Other lesions previously cited as possible manifestations of $\operatorname{IBD}^{(4,16)}$ were unusual in our sample and, therefore, did not reach statistical significance in the present study.

There was a greater presence of symptoms in active phase of IBD, $70.6 \%$ of cases in the active phase compared to only $52.1 \%$ of patients in remission, representing a statistically significant difference. A previous study, also pointed towards a higher incidence of oral manifestations in active period of the disease, however that study failed to demonstrate statistical significance ${ }^{(15)}$.

In our sample $10.8 \%$ of $\mathrm{CD}$ patients presented oral mucosa lesions against $11.4 \%$ of UC patients. This difference was not statistically significant. Other authors had already reported no significant differences in prevalence of lesions between both diseases ${ }^{(13)}$. However, there have been reports in the literature considering that $\mathrm{CD}$ is more affected by oral lesions than $\mathrm{UC}^{(15,17)}$.

Although other studies ${ }^{(8,9,12,19,20,24)}$ associate pyostomatitis vegetans and orofacial granulomatosis with IBD, these data could not be confirmed in our population, since they showed no occurrence of these lesions. The recent pharmacotherapy of IBD had significant impact on the natural history and clinical presentation of patients. Eventually, the absence of some classical oral lesions in our study, with a large number of patients, may be result of the modern treatment of IBD.

Small differences can be found regarding oral symptoms between UC and CD, and those were not statistically significant. Similar conclusions were already disclosed in Katz ${ }^{(15)}$ article, in which the author determined that even though both conditions showed a higher prevalence of oral symptoms compared with the control group, no significant differences existed between them.

In which regards pharmacological treatment, our results revealed that untreated patients were the least affected by oral manifestations, and salicylates represent the therapy with fewer side effects. Although no statistically significant relation was established, the $P$-value 0.052 shows a statistical trend towards a relation between some therapies and 
higher incidence of oral symptoms. Conversely, immunosuppressive therapy may be a surrogate marker of a more severe IBD and oral manifestations may be more frequent in those patients.

In our sample, non-smokers have been the most affected by oral mucosa lesions with $9.57 \%$ against $5.26 \%$ of smokers, although this difference was not statistically significant. $57.89 \%$ of smoking patients reported oral symptoms against $54.26 \%$ of non-smokers, which is not a statistically significant relation.

When considering lesions of the oral mucosa, we observed a trend towards increase in incidence over the course of IBD duration. For oral symptoms, there was a downward trend in incidence over the course of the disease, even though none of these relations proved to be statistically significant.

\section{CONCLUSION}

A positive association between inflammatory bowel disease and oral mucosa lesions was established in this study, being IBD patients more affected, particularly in active phases of the disease. Aphthous ulcers were the most significant expression of this group of manifestations.

The oral symptoms were also associated with IBD, with dysphagia being the most reported symptom. Oral symptoms proved to be even more prevalent in active periods of the disease.

The time since disease onset and pharmacological regimen may interfere with the incidence of oral lesions and symptoms, although in this study the differences detected were not statistically significant. Oral lesions seem to increase over time, while oral symptoms seem to decrease, what may be attributable to the fact that the ongoing drug therapy diminished these oral manifestations.

The association between IBD and oral mucosa lesions and symptoms represents a clinical challenge that should encourage dentists to plan a careful follow-up of these patients, with the support of the gastroenterologist, in order to provide a better integrated treatment for these conditions.

\section{Authors' contributions}

Laranjeira N, DMD, and Leitão J, PhD, MD, designed the study and participated in the interpretation of data, review, and approval of the manuscript. All authors had access to the data, contributed to the development of the content, reviewed each draft of the manuscript, and approved the final content.

Laranjeira N, Fonseca J, Meira T, Freitas J, Valido S, Leitão J. Lesões das mucosas orais e sintomatologia oral em doentes com Doença Inflamatória Intestinal. Arq Gastroenterol. 2015,52(2):105-10.

RESUMO - Contexto - A doença inflamatória intestinal é conhecida por suas manifestações extraintestinais, a cavidade oral não é exceção. Objetivos - O objetivo deste estudo foi o de avaliar a associação da doença inflamatória intestinal com lesões da mucosa oral e sintomatologia oral, e complementarmente, avaliar a sua possível relação com a higiene oral, tabagismo, terapêutica farmacológica, duração e atividade da doença. Métodos - Os pacientes foram selecionados no serviço de Gastroenterologia de um hospital de referência terciária Português (Hospital Garcia de Horta). Esta amostra foi composta por 113 pacientes previamente diagnosticados com colite ulcerosa ou doença de Crohn, juntamente com um grupo controle de 58 indivíduos saudáveis que acompanhavam os pacientes do grupo nas suas consultas de controle. Entrevistas clínicas e exames clínicos foram realizados para a coleta de dados. Resultados - Os pacientes do grupo de estudo foram mais afetados por sintomas orais $(P=0,011)$, e houve também uma tendência para uma maior incidência de lesões da mucosa oral, embora a significância estatística não tenha sido alcançada $(8,8 \%$ versus $3,4 \%$ no grupo de controle; $P=0,159)$. Pacientes em fase ativa foram os mais afetados. Não foram detetadas diferenças entre a doença de Crohn e a colite ulcerosa, ou relativas a hábitos tabágicos. $\mathrm{O}$ tratamento com corticosteroides e imunossupressores pareceu aumentar a incidência de sintomas orais $(P=0,052)$. Os dados são ainda compatíveis com aumento das lesões da mucosa oral e diminuição dos sintomas ao longo do curso da doença, no entanto, sem significância estatística. Conclusão - As lesões de mucosa oral e sintomas orais foram associados positivamente com a doença inflamatória intestinal, principalmente durante os períodos de atividade da doença e possivelmente, associado a terapêutica com corticosteroides e imunossupressores.

DESCRITORES - Doenças inflamatórias intestinais. Estomatite aftosa. Mucosa bucal. 


\section{REFERENCES}

1. Ardizzone S, Puttini PS, Cassinotti a, Porro GB. Extraintestinal manifestations of inflammatory bowel disease. Dig Liver Dis. 2008;40(Suppl 2):S253-9.

2. Asquith P, Thompson RA, Cooke WT. Oral manifestations of Crohn's disease. Gut. 1975;16(4):249-54.

3. Blumberg RS, Saubermann LJ, Strober W. Animal models of mucosal inflammation and their relation to human inflammatory bowel disease. Curr Opin Immunol. 1999;11(6):648-56.

4. Boisnic S. Cheilitis. Rev Prat. 2002;52(4):370 4.

5. Brito F, de Barros FC, Zaltman C, Carvalho ATP, Carneiro AJDV, Fischer RG, et al. Prevalence of periodontitis and DMFT index in patients with Crohn's disease and ulcerative colitis. J Clin Periodontol. 2008;35(6):555-60.

6. Daley TD, Armstrong JE. Oral manifestations of gastrointestinal diseases. Can J Gastroenterol. 2007;21(4):241-4.

7. Elahi M, Telkabadi M, Samadi V, Vakili H. Association of oral manifestations with ulcerative colitis. Gastroenterol Hepatol Bed Bench. 2012;5(3):155-60.

8. Fatahzadeh M. Inflammatory bowel disease. Oral Surg Oral Med Oral Pathol Oral Radiol Endod. Elsevier Inc.; 2009;108(5):e1-10.

9. Flemmig TF, Shanahan F, Miyasaki KT. Prevalence and severity of periodontal disease in patients with inflammatory bowel disease. J Clin Periodontol. 1991;18(9):690-7.

10. Galbraith SS, Drolet B a, Kugathasan S, Paller AS, Esterly NB. Asymptomatic inflammatory bowel disease presenting with mucocutaneous findings. Pediatrics. 2005;116(3):e439-44.

11. Gassull M, Gomollón F, Hinojosa J, Obrador A. Enfermedad Inflamatoria Intestinal. 3rd ed. Madrid: Arán Ediciones; 2007.

12. Grössner-Schreiber B, Fetter T, Hedderich J, Kocher T, Schreiber S, Jepsen S. Prevalence of dental caries and periodontal disease in patients with inflammatory bowel disease: a case-control study. J Clin Periodontol. 2006;33(7):478-84.

13. Habashneh R a, Khader YS, Alhumouz MK, Jadallah K, Ajlouni Y. The association between inflammatory bowel disease and periodontitis among Jordanians: a case-control study. J Periodontal Res. 2012;47(3):293-8.
14. Harvey RF, Bradshaw JM. A simple index of Crohn's-disease activity. Lancet. 1980;1(8167):514.

15. Katz J, Shenkman a, Stavropoulos F, Melzer E. Oral signs and symptoms in relation to disease activity and site of involvement in patients with inflammatory bowel disease. Oral Dis. 2003;9(1):34-40.

16. Leão JC, Hodgson T, Scully C, Porter S. Review article: orofacial granulomatosis. Aliment Pharmacol Ther. 2004;20(10):1019-27.

17. Lourenço S V, Hussein TP, Bologna SB, Sipahi a M, Nico MMS. Oral manifestations of inflammatory bowel disease: a review based on the observation of six cases. J Eur Acad Dermatol Venereol. 2010;24(2):204-7.

18. Neville BW, Damm DD, Allen CM, Bouquot JE. Patologia Oral e Maxilofacial. 2nd ed. Koogan G, editor. Rio de Janeiro; 2004.

19. Ojha J, Cohen DM, Islam NM, Stewart CM, Katz J, Bhattacharyya I. Gingival involvement in Crohn disease. J Am Dent Assoc. 2007;138(12):1574-81.

20. Pittock S, Drumm B, Fleming P, McDermott M, Imrie C, Flint S, et al. The oral cavity in Crohn's disease. J Pediatr. 2001;138(5):767-71.

21. Rampton D. Inflammatory Bowel Disease Clinical Diagnosis and Manegement London: Martin Dunitz; 2000.

22. Satsangi J, Morecroft J, Shah NB, Nimmo E. Genetics of inflammatory bowe disease: scientific and clinical implications. Best Pract Res Clin Gastroenterol. 2003;17(1):3-18.

23. Satsangi J, Silverberg MS, Vermeire S, Colombel J-F. The Montreal classification of inflammatory bowel disease: controversies, consensus, and implications. Gut. 2006;55(6):749-53.

24. Scheper HJ, Brand HS. Oral aspects of Crohn's disease. Int Dent J. 2002;52(3): 163-72.

25. Scully C, Cochran KM, Russell RI, Ferguson MM, Ghouri MA, Lee FD, et al. Crohn's disease of the mouth: an indicator of intestinal involvement. Gut. 1982;23(3):198-201.

26. Sleisenger MH. Pathophysiology of the gastrointestinal tract. In: Smith LH, Thie SO, editors. Pathophysiology: the biologic principles of disease. Philadelphia: The W. B. Sauders Co.; 1981. p. 1506-689.

Received 4/11/2014 Accepted 26/1/2015 